\title{
Conservative Blood Management in a Jehovah's Witness with Placenta Percreta: A Case Report and Transfusion Trigger Questioning
}

\author{
Paula Alves Pinheiro, Marina Ayres Delgado, Camila Biazussi Damasceno, Isadora Megale Quadros \\ Department of Anesthesia and Pain Medicine. Hospital das Clínicas de Minas Gerais, Belo Horizonte/Minas Gerais, Brazil.
}

\section{Corresponding Author:}

Dr Marina Ayres Delgado

Email: marina.ayres.delgado@gmail.com

This is an Open Access article distributed under the terms of the Creative Commons Attribution License (creativecommons.org/ licenses/by/3.0).

Received Accepted Published

December 1, 2020 April 13, 2021 May 20, 2021

\begin{abstract}
Background: Jehovah's witness is a Christian religion with 8.6 million worldwide members who recognize the Bible as God's message to humanity. Based on their interpretation of the Bible, blood is seen as holy and sacred and therefore blood component transfusions are not allowed. This is a special concern in cases of severe anemia and non-elective surgeries as there is no time to restore blood storages and reduce the risk of exogenous blood need. Case Report: Here we present the case of a 33-year-old Jehovah's Witness with an infected miscarriage and placenta percreta confirmed during operation. A nadir of $5.1 \mathrm{~g} / \mathrm{dL}$ hemoglobin was reached but, despite severe anemia, no hemodynamic instability or increased lactate levels were noticed and no blood components administrated. Conclusion: As blood transfusion carries in itself potential risks and is a special issue in this group of patients this report suggests that blood transfusions should be guided by personal triggers, based on hemodynamic and laboratorial levels associated with age and co-morbidities.
\end{abstract}

Keywords: Anemia; Blood Transfusion; Blood Component Transfusion, Jehovah`s Witnesses, Pregnancy.

\section{Introduction}

Placenta percreta constitutes the most serious variation of the spectrum of placental accretism. Although rare, its incidence has been increasing in recent decades due to higher rates of cesarean sections. Placenta percreta normally extends to extra-uterine tissue and, during the surgery, is associated with the risk of damage to local organs, neurovascular invasion, hemorrhage and disseminated intravascular coagulation. The standard treatment for this condition is cesarean hysterectomy, which has been associated with high maternal morbidity and peri-operative average blood loss of $4800 \mathrm{ml}$ in these cases [1]. Accretism may be detected by ultrasound and confirmed by magnetic resonance, however in some cases diagnosis is made only at the time of delivery, which compromises pre-operative planning. The anesthetic management of placenta percreta procedures is challenging, especially in case of Jehovah's Witnesses, who, according to their beliefs, do not allow transfusion of blood components.

\section{Case Report}

Patient a thirty-three-years-old Jehovah's Witness 35 weeks into gestation, previously healthy, preoperative hemoglobin $(\mathrm{Hb})$ of $13.1 \mathrm{~g} / \mathrm{dL}$ in use of iron sulfate, was admitted to our service due to infected miscarriage. She was being treated by a high-risk prenatal care team due to multiple fetal malformations, placenta previa and gestational diabetes. Placental accretism was suspected in previous image exams. Patient was previously oriented regarding possibility of massive perioperative bleeding and blood transfusion and an 
urgent hysterectomy. After standard monitoring, an 18-gauge venous access was punctured in the right upper limb and spinal anesthesia was performed with $12.5 \mathrm{mg}$ hyperbaric bupivacaine and $100 \mathrm{mcg}$ morphine. Epsilon aminocaproic acid $15 \mathrm{mg} / \mathrm{kg}$ was administered before the incision. During surgery, placenta percreta was identified with cervix and bladder invasion. Conversion to general anesthesia became necessary due to increased intra-operative bleeding and extended surgery time. Hysterectomy was performed and patient kept hemodynamically stable despite profuse bleeding.

After the procedure, patient was transferred to intensive care unit (ICU) extubated, with $7.2 \mathrm{~g} / \mathrm{dL}$ hemoglobin and 74,000 platelets. On the second post-operative day, the patient had an accentuated drop in hemoglobin levels and acute renal failure. She was then transferred to the operating room and underwent an exploratory laparotomy, which showed significant bladder bleeding and bilateral ureteral obstruction. No blood components were administered but transient norepinephrine became necessary in continuous infusion pump during the procedure. Once again, she returned to the ICU extubated, without metabolic acidosis despite having $5.1 \mathrm{~g} / \mathrm{dL}$ hemoglobin she remained stable during hospitalization, with the progressive improvement of the hematimetric levels. Even with severe anemia, lactate didn't reach higher levels. In addition, the patient did not present sustained hypotension or organ damage. She was discharged 11 days after the procedure, with $6.7 \mathrm{~g} / \mathrm{dL}$ hemoglobin count and rising.

\section{Discussion}

Blood component transfusions are relatively new therapy, becoming routine practice only after World War II. The first blood transfusions reported occurred in the $17^{\text {th }}$ century using animal blood $[2,3]$ and the first direct blood transfusion is attributed to James Blundell in 1818, after administering human blood to women that suffered from postpartum hemorrhage [4]. Since then, much has evolved regarding transfusion recommendation and safety, but in Jehovah's witnesses it remains an ethical challenge. Jehovah's witnesses refusal of blood products is based on interpretations of the biblical passages that show blood as sacred and holy, with the prohibition of any form of intake, under the penalty of community ostracism. Some blood products and fractions, on the other hand, can be accepted as they are considered "conscience items", which means that the individual can decide based on a review of his own conscience [5]. Medical teams should always aim to respect their beliefs and try not to transfuse until it is extremely necessary, which is sometimes a subjective and hard point.

Blood transfusion could be lifesaving but carries in itself the risk of infection, immunosuppression, immunoreactions, besides the high costs to the medical system. In the other hand, early diagnosis of anemia and immediate therapy is essential, mainly in patients who refuse blood transfusion. Severe anemia is defined as a hemoglobin less than $7 \mathrm{~g} / \mathrm{dL}$ and critical anemia is defined as a hemoglobin less than $5 \mathrm{~g} / \mathrm{dL}$ [2]. Blood conservation methods consist of techniques that minimize blood loss and improve patients' own supply with better outcomes [6,7] and it should be the first effort during any surgery, especially in Jehovah's Witnesses. Iron, vitamin B12, folic acid can be used to improve patient storage. Adequate treatment of hypertension and postoperative pain is also recommended. Treatment with anti-fibrinolytic agents can be considered in patients with increased risk of hemorrhage and in a life-threatening bleeding, prothrombin complex concentrates are approved for reversal of vitamin $\mathrm{K}$ antagonists [2]. Kidson-Gerber et al. propose intravenous iron administration in women suffering from severe post-hemorrhagic anemia because it increases hemoglobin levels faster than oral administration. Erythropoietin enhances 
hematopoietic function of bone marrow, but can lead to thrombotic complications. Therefore, the risks and benefits of erythropoietin should be considered in patients with high-risk bleeding [8]. Cell saver is an option to receive the patient's own blood from intra-operative salvage and should be an option if anticipated blood loss is $>20 \%$ of estimated total blood volume. Some data suggest that methotrexate induces placental necrosis and causes more rapid placental expulsion. There are also some promising therapies like hemoglobin-based oxygen carries, however, due to their potentially lethal side effects, they are not recommended [8].

Before the intervention, a meticulous coagulopathy research is important to avoid excessive bleeding. During surgery, controlled hypotension can help to obtain effective hemostasis. Many different approaches have been described to overcome the physiologic deficit resulting from low levels of hemoglobin. The need for transfusion should be on a case-to-case basis avoiding strictly fixed limit of hemoglobin. Studies demonstrated that a hemoglobin level of $5 \mathrm{mg} / \mathrm{dL}$ can maintain satisfactory tissue oxygenation. With this level, although oxygen carrying capacity is decreased, tissue oxygenation is still preserved due to increase of 2,3 diphosphoglycerate (DPG) concentrations with a right shift in the oxygen dissociation curve, increases of erythropoietin levels, increases of stroke volume, heart rate and consequently cardiac output [6]. Critical hemoglobin levels vary from patient to patient, depending on their individual oxygen needs and adaptative response [8]. According to the Frank-Starling law, increased circulating volume stretches the ventricular wall and, consequently, the cardiac muscle contracts more forcefully. Thus, fluid optimization guarantees an increase of cardiac index and maintains the balance between oxygen supply and oxygen consumption during surgery. The cardiac index has a predominant role in the maintenance of adequate delivery of oxygen (DO2), reducing levels of lactate, morbidity, mortality and wound infection. After surgery, the patient should stay with standard monitoring as a way to detect early bleeding, and the continuous optimization of cardiac index and guaranteed DO2 as it is associated to a fast recovery.

The patient of this report did not present hypoperfusion, organ damage or increase in lactate levels during her hospital stay. The prophylactic treatment with iron sulfate, the gestational increased blood volume associated with meticulous intraoperative care could explain her tolerance to the acute hemorrhage present during the procedures.

\section{Conclusion}

Major surgeries with high probability of bleeding remain challenge, especially in Jehovah's witnesses. Individual and dynamic transfusion triggers based on age, co-morbdities, hemodynamic and laboratorial parameters should be followed instead of fixed ones in order to avoid unnecessary transfusion.

Contributors: PAP and MAD were involved in planning and supervised the work, make substantial contributions to conception and design, participate in drafting the article, wrote the paper with input from authors. CBD and IMQ revising it critically. MAD will act as guarantor. All authors approved the final version of this manuscript and are responsible for all aspects of this study.

Funding: None; Competing interests: None stated.

\section{References}

1. Wong AJ, Schlumbrecht M, Huang M. Management of placenta percreta in a Jehovah's Witness patient. BMJ Case Rep. 2018;2018:2-5.

2. Crowe EP, Desimone RA. Transfusion support and alternatives for Jehovah's Witness patients. Current Opinion in Hematology. 2019;26:473-479.

3. Learoyd P. The history of blood transfusion prior to the $20^{\text {th }}$ century-part 2. Transfus Med. 2012;22(6):372-376.

4. Mason CLT, Tran CK. Caring for the Jehovah's Witness parturient. Anesth Analg. 2015;121(6):1564-1569.

5. Zeybek B, Childress AM, Kilic GS, Phelps JY, Pacheco LD, Carter MA. Management of the Jehovah's Witness in obstetrics and gynecology: A comprehensive medical, ethical and legal approach. Obstetrical \& Gynecological Survey. 2016;71:488. 
6. Hudgins K, Carter E. Blood conservation: Exploring alternatives to blood transfusions. Crit Care Nurs Q. 2019;42(2):187-191.

7. Rajewska A, Mikołajek-Bedner W, Sokołowska M, Lebdowicz J, Kwiatkowski S, Torbè A. The
Jehovah's Witness obstetric patient a literature review. Anaesthesiology Intensive Therapy. 2019;51:390-403.

8. ShanderA, Goodnough LT. Management of anemia in patients who decline blood transfusion. American Journal of Hematology. 2018;93:1183-1191. 